\title{
A prospective randomized study to compare analgesic and sedative effect of midazolam and nalbuphine with midazolam and fentanyl in patients undergoing awake fiberoptic intubation
}

\author{
Kaur Harpreet ${ }^{1}$, Singh Harjeet ${ }^{2}$, Mohan Brij ${ }^{3}$, Sood R Ojaswani ${ }^{4}$, Jaspreet $^{5}$ \\ ${ }^{1}$ Professor, ${ }^{2,3}$ Associate Professor, ${ }^{4,5}$ Junior Resident, Dept. of Anaesthesia, Government Medical College, Amritsar, Punjab, India
}

*Corresponding Author: Singh Harjeet

Email: drharjeet1960@gmail.com

Received: $19^{\text {th }}$ December, 2018

Accepted: $4^{\text {th }}$ February, 2019

\begin{abstract}
Introduction: Awake fiberoptic intubation (AFOI) under sedation and local anaesthesia is gold standard in anticipated difficult airway scenarios. Various drugs are used to achieve conscious sedation with adequate analgesia such as propofol, fentanyl, nalbuphine and midazolam. In this study, we compared the analgesic and sedative effects of fentanyl and midazolam with nalbuphine and midazolam in patients undergoing AFOI using spray as you go method.

Materials and Methods: 60 patients between the age of 18 and 60yrs of either sex, scheduled for elective surgery were included after taking written informed consent. Premedication with Inj. Glycopyrrolate $0.2 \mathrm{mg}$ i.m. 30 mins before and Inj. Midazolam $1 \mathrm{mg}$ i.v. 15 mins before the procedure was given. Then patients were randomly divided into 2 groups. Group $\mathrm{N}$ ( $\mathrm{n}=30$ ) received inj. nalbuphine $0.2 \mathrm{mg} / \mathrm{kg}$ i.v. and group B $(n=30)$ received inj. fentanyl $2 \mathrm{mcg} / \mathrm{kg}$ i.v., both $5 \mathrm{mins}$ prior to the introduction of fiberscope. The nasotracheal fiberoptic intubation was carried out using spray as you go technique. Level of sedation, intubation score and VAS score were observed along with patient comfort score.

Results: Group F patients had better sedation score $(\mathrm{P}=0.328)$, VAS score $(\mathrm{P}=0.184)$, significantly better intubation score $(\mathrm{P}=0.00)$, intubation time $(0.00)$ and patient comfort score $(\mathrm{P}=0.05)$. Hemodynamics (heart rate, systolic blood pressure, diastolic blood pressure) were significantly better in group F.

Conclusion: Fentanyl-midazolam combination for awake fibreoptic intubation using spray as you go technique, provided better sedation and analgesia, obtunded airway reflexes and minimized pressor response to awake fibreoptic intubation and provided better patient comfort.
\end{abstract}

Keywords: Fiberoptic, Intubation, Spray as you go, Fentanyl, Nalbuphine.

\section{Introduction}

An anesthesiologist's expertise in airway management is of paramount importance in emergent and elective conditions to maintain oxygenation and prevent aspiration. The incidence of failure to secure an adequate airway has been estimated to be $3-18 \%$ and is the most common cause of mortality and serious morbidity due to anaesthesia. ${ }^{1}$

Although an array of techniques and armamentarium are available to secure difficult airway, awake fiberoptic intubation (AFOI) under sedation and local anaesthesia, is considered as gold standard by experts, in compromised airway situations. ${ }^{2}$ Success in this procedure and patient comfort depends hugely on the skill of the clinician as well as the preparation of equipment and patient, among which topicalization of airway and adequate premedication with antisialogogue plays a vital role. ${ }^{3}$ Authors have described various methods for locally anaesthetizing the airways to abolishing cough and gag reflexes. They include spray as you go technique, nebulization of airways with local anesthetic agents and administration of airway blocks. ${ }^{4,5}$ Spray as you go technique is preferred technique since it is non-invasive and effective.

Conscious sedation is a major contributory factor for setting a scene for quiet, co-operative, communicative, pain free and spontaneously breathing patient undergoing AFOI. Propofol, fentanyl, dexmedetomidine, midazolam etc. can be used to achieve conscious sedation along with adequate analgesia during AFOI. ${ }^{6,7}$

In our study, we compared the analgesic and sedative effects of fentanyl and midazolam with nalbuphine and midazolam in patients undergoing awake fiberoptic intubation. The primary objectives of our study were to observe the level of sedation, intubation score and VAS score after completion of procedure. The secondary objectives included assessment of patient comfort, intubation time, hemodynamic changes and complications.

\section{Materials and Methods}

After approval from Institutional Ethical Committee and written informed consent 60 patients of American Society of Anesthesiologist (ASA) grade I and II, either sex, 18-60 years of age, posted for elective surgeries were enrolled in this prospective, randomized controlled study. All the patients had anticipated difficult airway with either Mallampatti grade III or IV or Wilsons score $>6$ or higher Body Mass Index (BMI). Patients who refused for consent, had emergency surgeries, patients with airway pathologies or with history of bronchial asthma or arrhythmias were excluded from the study. After detailed pre-anaesthetic checkup (including complete airway assessment) routine fasting guidelines was explained and anti-aspiration prophylaxis was given to all the patients night before the surgery. 
On the operation table, standard monitoring techniques including electrocardiography, noninvasive blood pressure (NIBP) and pulse oximetry (SpO2) were performed on all patients. Intravenous line (i.v.) was secured and ringer lactate infusion started. After recording the baseline blood pressure (BP), heart rate (HR) and oxygen saturation, all the patients were given injection (inj.) glycopyrrolate $0.2 \mathrm{mg}$ intramuscularly (i.m.) 30 minutes before starting the procedure. The patency of both the nares was checked and 4 drops of xylometazoline nasal drops were instilled in the more patent nostril. Inj. midazolam $0.05 \mathrm{mg} / \mathrm{kg}$ was given 15 mins prior to intubation. 2 puffs of $10 \%$ lignocaine were sprayed on posterior pharyngeal wall and the patient was asked to withhold as much of $10 \%$ of lignocaine as possible. This locally anaesthetized the posterior pharyngeal wall. The patients were randomly allocated into two groups-group $\mathrm{N}$ and group $\mathrm{F}$ by using chit and box method of randomization.

Group $\mathrm{N}$ patients were given inj. nalbuphine $(0.2$ $\mathrm{mg} / \mathrm{kg}$ ) i.v. and group F patients were given inj. Fentanyl (2 $\mu \mathrm{g} / \mathrm{kg}$ ) i.v. both five mins before intubation. The level of sedation was assessed at this moment using Observer's Assessment of Alertness/sedation (OAS) score. Then a lubricated nasopharyngeal airway of appropriate size was inserted in the contralateral nostril. The breathing circuit was connected to the end of this airway administering $100 \%$ oxygen during the procedure. Two milliliter $(\mathrm{ml})$ aliquots of $4 \%$ Lignocaine with $3 \mathrm{ml}$ air was loaded into 4 separate syringes and kept ready for instillation in the working channel of fiberscope.

A fiberoptic bronchoscope (FOB) with diameter 3.5 $\mathrm{mm}$ with a working channel for drug instillation, was lubricated with aqueous gel and loaded with the polyvinyl chloride, cuffed endotracheal tube (ETT) (size 6.0 to 7.0). After applying 2\% lignocaine jelly into the prepared nostril, fiberscope was introduced and advanced to the nasopharynx and oropharynx while visualizing the structures. Lignocaine $4 \%$ was administered in aliquots of two $\mathrm{mL}$ each through the working channel of the fiberscope at four levels: epiglottis, supra glottis area, subglottic area and in distal trachea after visualization of the carina (total lignocaine dose $=360 \mathrm{mg}$ ). After instilling each aliquot, the bronchoscopist waited for 30 to 40 seconds before proceeding further. However, the total dose of lignocaine was calculated and was never more than five $\mathrm{mg} / \mathrm{kg}$ of the body weight.

The bronchoscopist then asked the assistant to slide the tube (with lubricated tip) over the fiberscope while the fibrescope was held in position. The carina was always kept in the field of vision to prevent dislocation of fiberscope. 3$5 \mathrm{~cm}$ above the carina the ETT was fixed in place and connected to the anaesthetic breathing circuit. The placement of tube was confirmed with direct vision on the screen and by using capnography. General anaesthesia was then induced and maintained to provide anaesthesia, amnesia, analgesia and muscle relaxation during the surgery.
During the procedure the following observations were recorded and compared.

1. Hemodynamic profile including systolic blood pressure, diastolic blood pressure, mean arterial pressure (MAP) and $\mathrm{HR}$ at baseline and every $1 \mathrm{~min}$ till the end of intubation and every two minutes till ten minutes after the intubation.

2. The level of sedation using OAS score before starting intubation. Score 5=Appropriate verbal response to patient's name, score 4= Lethargic response, score $3=$ Response only when name is spoken loudly, score $2=$ Response after mild shaking, score $1=$ Response after painful stimuli and score $0=$ No response

3. Intubation score - this score included observation of vocal cord movement (score 1=open, score $2=$ moving, score $3=$ closing, score $4=$ closed), cough score (score $1=$ none, score $2=$ slight, score $3=$ moderate, score $4=$ severe) and limb movements (score $1=$ no movements, score $2=$ slight, score $3=$ moderate, score 4=severe)

4. Intubation time-from inserting the fiberscope to confirmation of nasotracheal intubation by appearance of end tidal CO2 (EtCO2) curve.

5. Number of attempts of intubation.

6. Patient tolerance was assessed by comfort score, whose value was the sum of five point patient comfort score ( $1=$ no reaction, $2=$ slight grimacing, $3=$ heavy grimacing, $4=$ verbal objection, $5=$ defensive movement of head or hands) and three point patient comfort score which had scores of 1 to 3 (1=cooperative, $2=$ restless or minimal resistance, $3=$ severe resistance)

7. Patient satisfaction score - a subjective assessment. This was enquired from patient after extubation, in the recovery room. Patient satisfaction score was graded as 1=Excellent, 2=Good, 3=Reasonable, 4= Poor.

8. VAS score was assessed at the end of surgery in the post-operative recovery room.

\section{Results}

The sample size was decided after consulting statistician taking into account the primary aims. Thus, a sample size of 30 patients in each group was considered to detect a significant difference between the two groups with an alpha risk of 0.05 and beta risk of 0.2 .

The data was collected in performa and statistically analysed with software IBM SPSS (Statistical Package for Social Sciences) version 23.0. The continuous variables (quantitative data) such as age, BMI, heart rate, blood pressure etc. were presented as mean \pm standard deviation and analysed by applying Student's t-test. The categorical variables (qualitative data) were analysed by Chi-square test. $\mathrm{P}<0.05$ was considered statistically significant.

The demographic profiles of both the groups were comparable with respect to age $(\mathrm{P}=0.53), \mathrm{BMI}(\mathrm{P}=0.122)$, ASA grade $(\mathrm{P}=0.71)$, MP grading $(\mathrm{P}=0.983)$ and Wilson score $(\mathrm{P}=0.288)$. (Table 1$)$

Baseline heart rates (HR) in group $\mathrm{F}$ was $85.67 \pm 7.95$ beats per minute $(\mathrm{bpm})$ and in group $\mathrm{N}$ was $84.50 \pm 6.53$ 
bpm. This was found to be comparable ( $\mathrm{P}=0.27)$. After five mins of drug administration, HR decreased significantly in both the groups. In group $\mathrm{F}$ decrease was $8.95 \%$ $(78.00 \pm 5.85 \mathrm{bpm})$ whereas in group $\mathrm{N}$ it was $3.16 \%$ decrease $(81.83 \pm 5.94 \mathrm{bpm})(\mathrm{P}=0.01)$. During intubation maximum increase mean HR in group $\mathrm{F}$ was $10.89 \%$ from the baseline ( $95 \pm 10.09 \mathrm{bpm})$ while Group N showed a much higher positive variation with increase of $16.62 \%$ from baseline $(98.54 \pm 3.87 \mathrm{bpm})$. HR returned to baseline values at four mins in group $\mathrm{F}$ and at six mins in group $\mathrm{N}$. Also, ten mins after intubation HR in group $\mathrm{F}$ was $7.04 \%(78.63 \pm 5.18$ bpm)lower than baseline while HR in group $\mathrm{N}$ was 8.84\%(77.03 $\pm 9.48 \mathrm{bpm})$ lower than baseline which was statistically non-significant $(\mathrm{P}=0.21)$. (Fig. 1)

The baseline mean arterial pressure (MAP) were comparable between group $\mathrm{F}(93.52 \pm 7.14 \mathrm{~mm} \mathrm{Hg})$ and group $\mathrm{N}(93.55 \pm 5.38 \mathrm{~mm} \mathrm{Hg})(\mathrm{P}=0.49)$. After five mins of drug administration, MAP significantly decreased in both the groups $(\mathrm{P}=0.02), 89.12 \pm 6.14 \mathrm{~mm}$ of $\mathrm{Hg}$ in group $\mathrm{F}$ (4.70\% decrease) and $92.16 \pm 4.81 \mathrm{~mm}$ of $\mathrm{Hg}$ in group $\mathrm{N}$ (1.49\% decrease).After intubation, a significant increase of $6.28 \%(99.39 \pm 4.75 \mathrm{~mm}$ of $\mathrm{Hg}$ ) in group $\mathrm{F}$ and $13.91 \%$ (106.57 \pm 5.21$)$ in group N $(\mathrm{P}=0.00)$ was observed. Group $\mathrm{F}$ patients showed fall in MAP values from the baseline value six mins after intubation whereas no such change was seen in group N. At 10 mins after intubation MAP in group $\mathrm{F}$ was $4.44 \%$ lower than baseline values $(89.37 \pm 4.88 \mathrm{~mm}$ of $\mathrm{Hg}$ ), while in group $\mathrm{N}$ was $4.06 \%$ higher than baseline values $(97.35 \pm 4.85 \mathrm{~mm}$ of $\mathrm{Hg}$ ). (Fig. 1)

The mean $\mathrm{SpO} 2$ values were comparable in both the groups and were $>95 \%$ throughout the procedure.

The level of sedation in both the groups was assessed by OAS score. Twenty three out of thirty patients (76.7\%) in group $\mathrm{F}$ had OAS score $\leq 3$ (three patients had score 2 and twenty patients had score 3 ) while only seventeen out of thirty patients $(56.6 \%)$ in group $\mathrm{N}$ had OAS score $\leq 3$ (one patient had score 2 and sixteen patients had score 3). Group F had six out of thirty (20\%) of patients with score 4 whereas group $\mathrm{N}$ had ten out of thirty $(33.3 \%)$ patients with OAS score of 4 . Also, only one out of thirty, $3.3 \%$ in group $\mathrm{F}$ had OAS score of 5 while three out of thirty, $10 \%$ in group $\mathrm{N}$ had OAS score of 5.The difference between the two groups is statistically non-significant $(\mathrm{P}=0.328)$.(Fig. 2$)$

The mean intubation time taken in group $\mathrm{F}$ was $3.54 \pm 0.33$ minutes and in group $\mathrm{N}$ was $4.45 \pm 0.32$ minutes. The mean intubation time in both the groups had statistically significant difference $(\mathrm{P}=0.00)$. (Table 2$)$

Intubating conditions in each patient were graded according to vocal cord movement, cough score and limb movement score, which showed non-significant difference between the two groups but were more procedure friendly in group fentanyl. The sum of these three parameters was noted as the mean intubation score, which was significantly better in group receiving Fentanyl (group F was 5.26 \pm 0.82 and in group $\mathrm{N}$ was $6.96 \pm 1.67)$. The two groups showed statistically significant difference $(\mathrm{P}=0.00)$. (Table 3$)$

All the patients were successfully intubated using awake-fiberoptic intubation and no procedure was cancelled due patient discomfort. A second intubation attempt with slight jaw lift was required in five patients of group $\mathrm{F}$ and ten patients of group $\mathrm{N}$.

Mean patient comfort score was calculated by summation of 5 point and 3 point patient comfort score. Group F, with score of $3.00 \pm 0.90$ showed significantly better comfort than group $\mathrm{N}$ with score of $2.36 \pm 0.55$ $(\mathrm{p}=0.05)$. (Table 2$)$

Patient satisfaction score was assessed in the recovery room. $50 \%$ of the patients in group F (15 out of 30) showed excellent satisfaction versus $36.7 \%$ patients in group $\mathrm{N}$ (11 out of 30). $36.7 \%$ patients in both the groups showed good satisfaction (11 out of 30 each). While only $13.3 \%$ patients in group F (4 out of 30) and $26.7 \%$ patients in group N (8 out of 30) showed reasonable satisfaction. Overall the values in both the groups were comparable and nonsignificant ( $\mathrm{P}=0.377$ ). (Fig. 3)

Group F had better VAS score of $1.90 \pm 0.54$ than group $\mathrm{N}$ with $2.10 \pm 0.52$. Both the groups were comparable in this respect $(\mathrm{P}=0.184)$. (Table 2$)$

\section{Discussion}

Awake FOB is considered as the mainstay for management of difficult airway scenarios due to its potential of preserving the tone of the airway structures for spontaneous ventilation. This demands meticulous pharmacological and mental preparation of the patient to alleviate anxiety and achieve patient comfort during the procedure. Conscious sedation using various classes of drugs and locally anaesthetizing the airway is the primary need. The present study was undertaken to compare the analgesic and sedative effects of fentanyl with midazolam and nalbuphine with midazolam using spray as you go method of airway topicalization in patients undergoing nasotracheal AFOI.

In a study it was concluded that four $\mathrm{ml}$ of $4 \%$ lignocaine sprayed into larynx using spray as you go technique was superior to the rest of the techniques (nerve block and airway nebulization). ${ }^{5}$ So we preferred this technique.

Fentanyl with midazolam improved the quality of sedation, provides good anxiolysis and amnesia without cardiorespiratory depression. This combination has been proved to provide better patient comfort and sedation in patients undergoing awake blind nasotracheal intubation. ${ }^{8}$

In our study fentanyl and nalbuphine were given five minutes before commencing fiberoptic intubation. This time was considered optimum to administer these drugs to provide adequate sedation and analgesia and to prevent circulatory responses to tracheal intubation. ${ }^{9}$ In a study fentanyl $(2 \mu \mathrm{g} / \mathrm{kg})$ was given at different times before intubation and observed that optimal injection time five minutes before intubation. ${ }^{10}$ Also, another trial concluded that nalbuphine given in dose of $0.2 \mathrm{mg} / \mathrm{kg} \mathrm{3}-5$ mins before laryngoscopy prevents stress response. ${ }^{11}$

The demographic profile including age, sex, BMI and ASA grades were comparable between the two groups 
$(\mathrm{P}>0.05)$. MPG and Wilson score values were also statistically non- significant between the groups.

Mean heart rate decreased significantly in both the groups after five mins of drug administration. A similar decrease in heart rate in Fentanyl group after induction was seen in clinical trial in 2002. ${ }^{12}$ In our study the maximum increase in mean heart rate at the end of intubation was $10.89 \%$ in group F and $16.62 \%$ in group N. Similar results were seen in a study showing maximum increase in the heart rate after intubation was $12.5 \%$ in group Fentanyl and $13.1 \%$ in group Nalbuphine. ${ }^{9}$ Thus heart rate in group Nalbuphine showed much higher positive variation than Fentanyl group. At two and four mins the fall in heart rate was clinically significant $(\mathrm{P}=0.01$ and 0.00 respectively). At four mins, in group $\mathrm{F}$ and at six mins in group $\mathrm{N}$ mean heart rate values were found to be lower than the baseline values. Similar findings were also quoted by many authours in their respective studies. ${ }^{12,13}$ Thus our study in consensus with previous studies showed better control of heart rate in group $\mathrm{F}$ as compared to group $\mathrm{N}$.

On comparison of MAP after five mins of drug administration, there was significant decrease $(\mathrm{P}=0.00)$ in MAP in both the groups, which was more in group $\mathrm{F}$. During intubation the mean values of MAP were significantly higher in group $\mathrm{N}$ than in group $\mathrm{F}(\mathrm{P}=0.00)$. At six mins after intubation in group $\mathrm{F}$ mean MAP reached the baseline value and at ten mins it was $89.37 \pm 4.88 \mathrm{~mm}$ of $\mathrm{Hg}$, which is $4.4 \%$ below the baseline value. Our study showed better MAP control in group F. This result was similar to the result concluded in a trial that showed that there was a significant attenuation of MAP in group Fentanyl for all recorded time periods. ${ }^{14}$

$\mathrm{SpO}_{2}$ values during and after intubation remained $>90 \%$ in all the cases due to para-oxygenation using nasopharyngeal airway throughout out the procedure. In a trial it was found that 25 out of 30 patients given Fentanyl had $\mathrm{SpO}_{2}$ of $\leq 94 \%$, which they managed by administration of oxygen through the working channel of bronchoscope. ${ }^{15}$

Level of sedation was analysed in both the groups using OAS score. $76.7 \%$ patients in fentanyl group and $56.6 \%$ patients in nalbuphine group had score $\leq 3(\mathrm{P}=0.328)$. This shows fentanyl provides relative deeper sedation. The similar level of sedation was observed in other studies conducting awake fibreoptic intubation using opioids. ${ }^{16}$

The mean intubation score in group $F$ was $5.26 \pm 0.82$ and in group $\mathrm{N}$ was $6.96 \pm 1.67(\mathrm{p}=0.00)$. Although the three parameters for its calculation were statistically nonsignificant, fentanyl group provided better intubating conditions over nalbuphine and hence we obtained a significant value of intubation score.

The mean intubation time in group $\mathrm{F}$ was $3.54 \pm 0.33$ minutes and in group $\mathrm{N}$ was $4.45 \pm 0.32$ minutes $(\mathrm{p}=0.00)$. Fentanyl group had lesser intubation time due to better sedation, analgesia, intubation score and hemodynamic profile. Hence, it provides better tolerance to the procedure.

Another trial showed lesser intubation time (4.2 \pm 1.2 mins) using Sufentanil using spray as you go technique. ${ }^{16}$

In a study, the authors successfully achieved awake nasotracheal intubation using spray as you go technique in 3.5-3.8 minutes. $^{17}$

Intubation attempts in our study were comparable between two groups $(\mathrm{p}=0.136)$ similar to that studied by Sethi et al. ${ }^{2}$ A second attempt was needed in five patients $(16.7 \%)$ in group $\mathrm{F}$ and ten patients $(33.3 \%)$ in group $\mathrm{N}$ with additional jaw thrust.

The mean comfort score (sum of 5 point and 3 point patient comfort score) in group $\mathrm{F}$ was $2.36 \pm 0.55$ and in group $\mathrm{N}$ was $3.00 \pm 0.90(\mathrm{P}=0.05)$. This showed that the patients in group $\mathrm{F}$ were more comfortable during the procedure. This was in concordance to observations by various other authors. ${ }^{16,18}$

After completion of surgery, satisfaction scores were evaluated. Both the groups had comparable satisfaction scores $(\mathrm{P}=0.377)$. These were similar to the scores obtained in study using similar technique for awake fiberoptic intubation. $^{16}$

Our study showed comparable VAS scores $(\mathrm{p}=0.184)$. This was similar to the results by various other trials, who concluded that majority of patients after giving $2 \mu \mathrm{g} / \mathrm{kg}$ Fentanyl had no recall (VAS 0-1) and $35 \%$ had trivial memories (VAS 2). ${ }^{8,12}$

There was no complication seen among both the group

Table 1: Demographic profile and airway assessment parameters

\begin{tabular}{|c|c|c|c|}
\hline Data & Group F & Group N & P value \\
\hline Mean age (years) & $35.60 \pm 8.93$ & $40.80 \pm 11.34$ & 0.53 (N.S) \\
\hline Sex (male:female) & $1: 1$ & $7: 8$ & $0.122($ N.S) \\
\hline BMI & $28.33 \pm 3.60$ & $27.17 \pm 2.78$ & \\
\hline ASA grade & & & 0.718 (N.S) \\
I & 25 & 26 & \\
II & 5 & 4 & 0.989 (N.S) \\
MPG & 12 & 12 & \\
Grade 1 & 6 & 7 & 0.288 (N.S) \\
Grade 2 & 8 & 7 & \\
Grade 3 & 4 & $7.03 \pm 1.09$ & \\
Grade 4 & $7.40 \pm 1.27$ & & \\
\hline Wilson score & & & \\
\hline
\end{tabular}

Data is displayed as mean \pm standard deviation or ratio. BMI: Body mass index; ASA: American society of anesthesiologists; MPG: Mallampati grading 
Table 2: Mean comfort score, intubation time, VAS score

\begin{tabular}{|l|c|c|c|}
\hline \multicolumn{1}{|c|}{ Parameters } & Group F & Group N & P value \\
\hline Mean comfort score & $2.36 \pm 0.55^{*}$ & $3.00 \pm 0.90$ & $0.05(\mathrm{~S})$ \\
\hline Intubation time(mins) & $3.54 \pm 0.33^{*}$ & $4.45 \pm 0.32$ & $0.00(\mathrm{~S})$ \\
\hline VAS score & $1.90 \pm 0.54$ & $2.10 \pm 0.52$ & 0.184 (N.S) \\
\hline
\end{tabular}

Data is displayed as mean \pm standard deviation. *Statistically significant compared to group N.VAS: Visual acuity scale.

Table 3: Vocal cord movement, cough score, limb movement and intubation score.

\begin{tabular}{|c|c|c|c|c|}
\hline \multirow{2}{*}{\multicolumn{2}{|c|}{ Parameters }} & \multicolumn{2}{|c|}{ Group } & \multirow[b]{2}{*}{$P$ value } \\
\hline & & Fentanyl & Nalbuphine & \\
\hline \multicolumn{5}{|c|}{ Vocal cord movements } \\
\hline Open (1) & No of patients. & 11 & 9 & \multirow{4}{*}{$0.313(\mathrm{NS})$} \\
\hline Moving (2) & No. of patients & 17 & 15 & \\
\hline Closing (3) & No. of patients & 2 & 6 & \\
\hline Closed (4) & No. of patients & 0 & 0 & \\
\hline \multicolumn{5}{|l|}{ Coughing } \\
\hline None(1) & No of patients. & 5 & 3 & \\
\hline Slight (2) & No. of patients & 21 & 19 & $0.380($ N.S) \\
\hline Moderate (3) & No. of patients & 4 & 8 & \\
\hline Severe(4) & No. of patients & 0 & 0 & \\
\hline \multicolumn{5}{|l|}{ Limb movements } \\
\hline None(1) & No. of patients & 17 & 10 & \multirow{4}{*}{$0.191(\mathrm{NS})$} \\
\hline Slight(2) & No. of patients & 10 & 15 & \\
\hline Moderate(3) & No. of patients & 3 & 5 & \\
\hline Severe (4) & No. of patients & 0 & 0 & \\
\hline \multicolumn{2}{|c|}{ Mean intubation score } & $5.26 \pm 0.82 *$ & $6.96 \pm 1.67$ & $0.00(\mathrm{~S})$ \\
\hline
\end{tabular}

Data is displayed as mean \pm standard deviation. *Statistically significant compared to group $\mathbf{N}$.

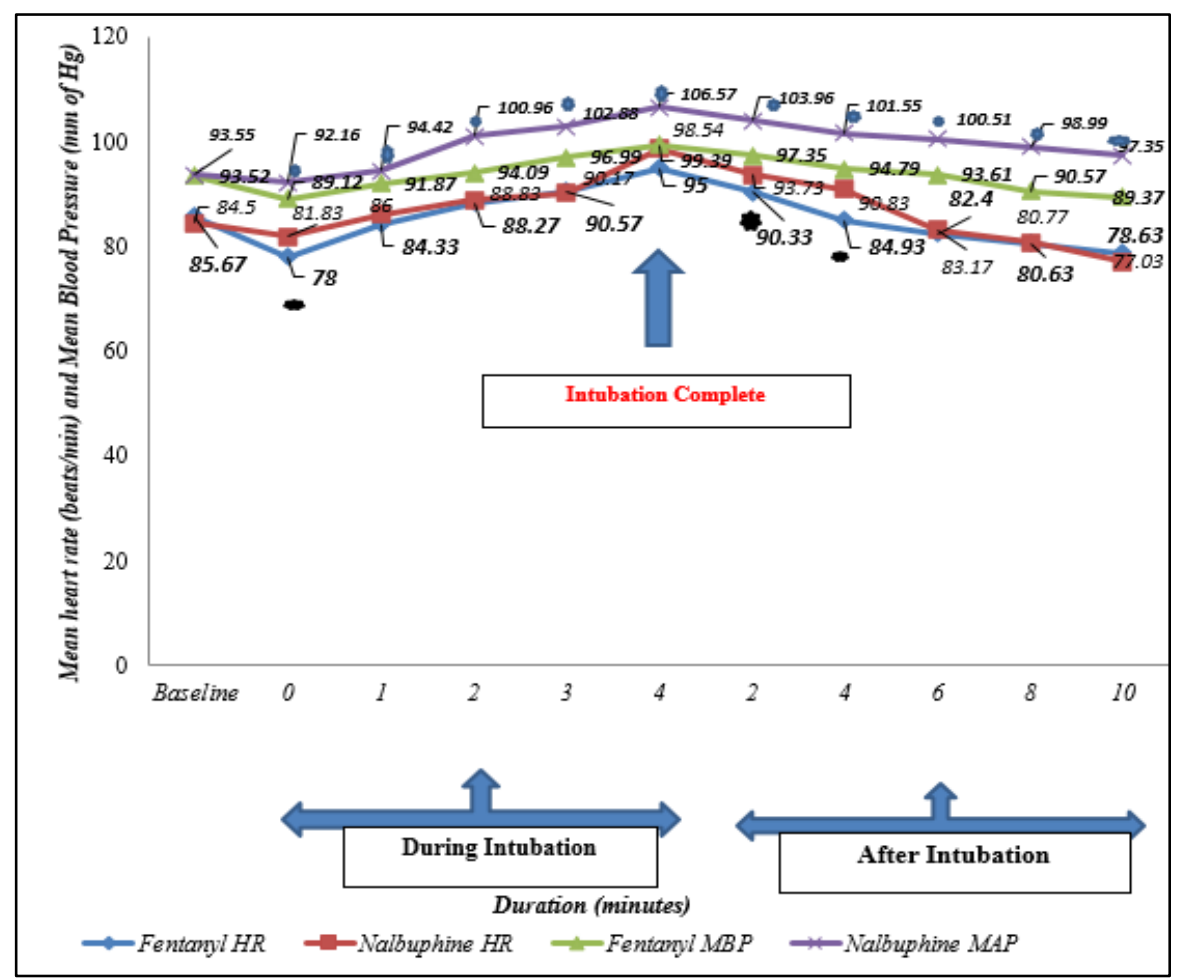

Fig. 1: Mean HR and MAP in group fentanyl and nalbuphine during and after intubation. Showing mean heart rate and mean blood pressure in both the groups during and after intubation.*shows significant difference between the groups. MBP: Mean blood pressure; HR: heart rate 


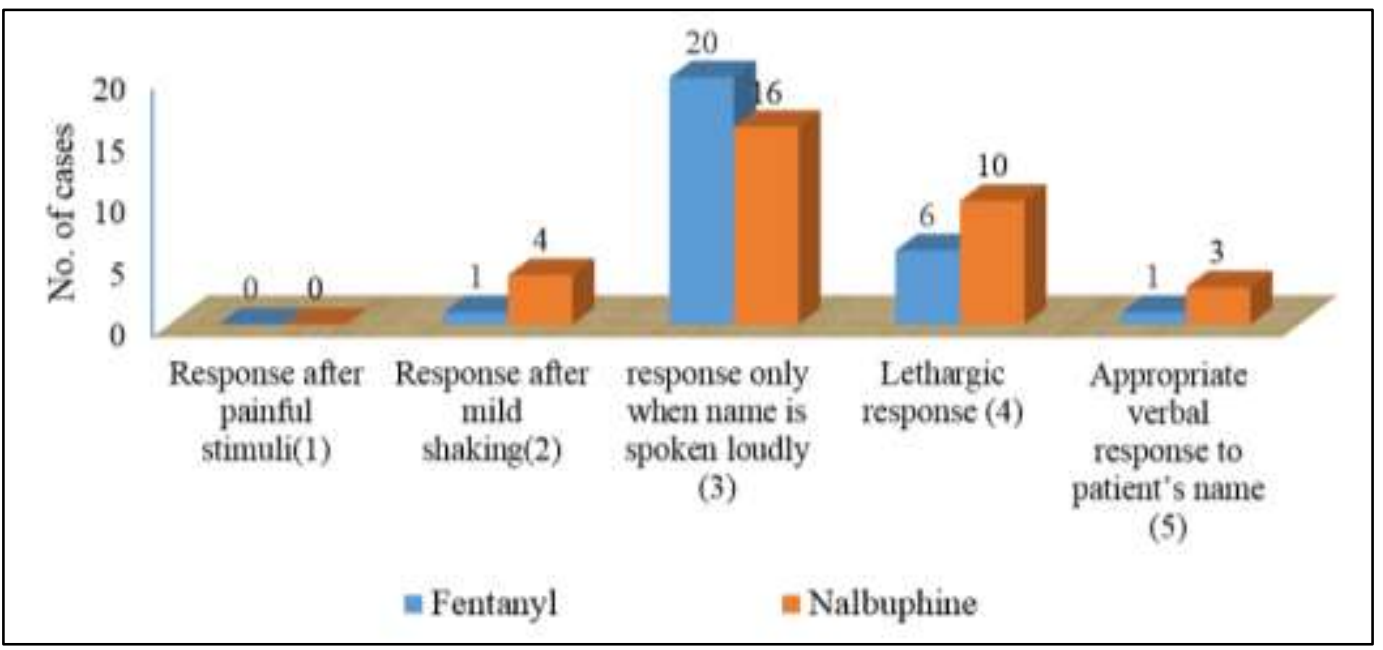

Fig. 2: Observer's Assessment of Sedation (OAS) score. Showing OAS score between group fentanyl and nalbuphine Better sedation score seen in group fentanyl

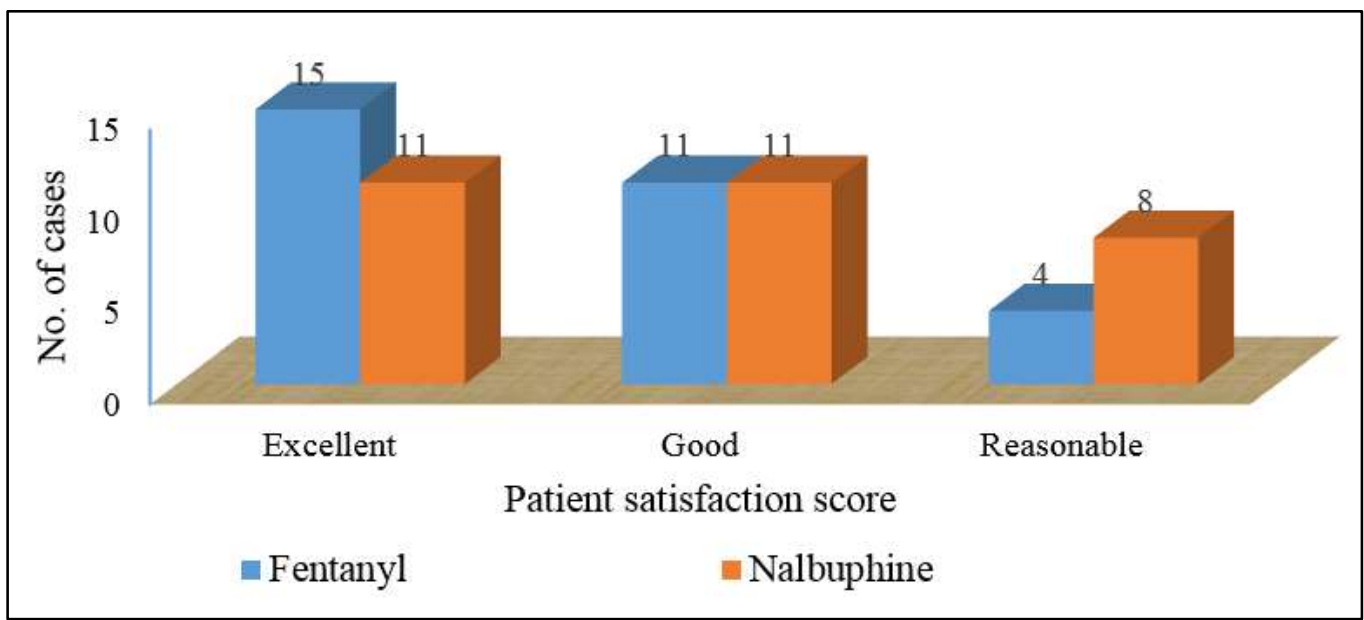

Fig. 3: Patient satisfaction score. Showing satisfaction score among two groups evaluated after the surgical procedure

\section{Conclusion}

From our study we concluded that Fentanyl-midazolam when compared with nalbuphine- midazolam, using spray as you go technique for awake fiberoptic intubation, provided better sedation and analgesia, obtunded airway reflexes, minimized pressor response to awake fiberoptic intubation and provided better patient comfort.

\section{Limitations of Study: Nil.}

\section{Financial Support and Sponsorship: Nil.}

Conflicts of Interest: None.

\section{References}

1. Wilson ME, Spiegelhalter D, Robertson JA, Lesser P. Predicting difficult intubation. Br J Anaesth 1988;61(2):211-6.

2. Slavkoviu Z, Stamenkoviu DM, Romiu P, Tomiu A, Miloviu $\mathrm{N}$, Jovanoviu $\mathrm{M}$ et al. The present and future of fiberoptic intubation. Vojnosanit Pregl 2013;70(1):61-7.

3. Murphy, Peter. A fibreoptic endoscope used for nasal intubation. Anaesth 1967;22(3);489-91.
4. Ovassapian A. Fibreoptic tracheal intubation in adults. In: Ovassapian A, ed. Fiberoptic endoscope and the difficult airway. Philadelphia: Lippincott-Raven 1996;7:1591-3.

5. Sethi N, Tarneja VK, Madhusudanan TP, Shouche S. Local Anaesthesia for Fiberoptic Intubation. Med J Armed Forces Ind 2005:61(1):22-5.

6. Lee JH, Han SW, Kim YY, Yum KW. Sedation and Hemodynamic Stability during Fiberoptic Awake Nasotracheal Intubation: Comparison between Propofol Infusion and Intravenous Boluses of Fentanyl and Midazolam. Kor J Anesthesiol 1997;33(4):741-9.

7. Lee JH, Han SW, Kim YY, Yum KW. Sedation and Hemodynamic Stability during Fiberoptic Awake Nasotracheal Intubation: Comparison between Propofol Infusion and Intravenous Boluses of Fentanyl and Midazolam. Kor J Anesthesiol 1997;33(4):741-9.

8. Dhasmana S, Singh V, Pal US. Awake Blind Nasotracheal Intubation in Temporomandibular Joint Ankylosis Patients under Conscious Sedation Using Fentanyl and Midazolam. $J$ Maxillofac Oral Surg 2010;9(4):377-81.

9. Sharma N, Parikh H. a comparitive study of hemodynamic responses to intubation: fentanyl versus Nalbuphine. Gujarat Med J 2014;69(2):49-53.

10. Ko Sh, Kim DC, Han YJ. Small dose fentanyl: optional time of injection for blunting the circulatory responses to tracheal intubation. Anaesth Analog 1998;86:658-61. 
11. Chawda PM, Pareek MK, Mehta KD. Effect of Nalbuphine on hemodynamic reponse to orotraheal intubation. J Anaesth Clin Pharmacol 2010;26(4);458-60.

12. Khan FA, Comparison of fentanyl and Nalbuphine in total intravenous anaesthesia (TIVA). J Pak Med Assoc 2002;52(10):459-65.

13. Rajlaxmi Bhandari, Shivani Rastogi, Amit Tyagi, Anumeha Joshi, Nimisha Malik, Anshul Sachdeva, Shomik. Attenuation of hemodynamic Response to endotracheal Intubation with Nalbuphine and Fentanyl: A Comparative Study. J Evol Med Dent Sci 2015;4(64):11172-81.

14. Channaiah VB, charry K, Vik JL. Clinical research: low dose fentanyl: Hemodynamic response to endotracheal intubation in normotensive patients. Arch Med Sci 2008;4(3):293-9.

15. Mondal S, Ghosh S, Bhattacharya S, Choudhury B, Mallick S, Prasad A. Comparison between dexmedetomidine and fentanyl on intubation conditions during awake fiberoptic bronchoscopy: A randomized double-blind prospective study. $J$ Anaesthesiol Clin Pharmacol 2015;31:212-6.

16. Li CW, Li YD, Tian HT, Kong XG, Chen K.

Dexmedetomidine-Midazolam versus Sufentanil-Midazolam for awake fiberoptic nasotracheal intubation: A randomised Double-blind Study. Chin Med J 2015;128:3143-8.

17. Tsai CJ, Chu KS, Chen TI, Lu DV, Wang Hm, Lu IC. A comparison of the effectiveness of dexmedetomidine vesus propofol target controlled infusion for sedation during awake fibreoptic intubation. Anaesth 2010;65:254-9.

18. Sharma J, Purohit S, Bhatia S, Kalra P, Sharma M, Meena R. Awake orotracheal fibreoptic intubation: Comparison of two different doses of Dexmedetomidine on intubation conditions in patients undergoing cervical spine surgery. Indian J Anaesth 2017;61:811-7.

How to cite this article: Harpreet $\mathrm{K}$, Harjeet S, Brij M, Ojaswani RS, Jaspreet. A prospective randomized study to compare analgesic and sedative effect of midazolam and nalbuphine with midazolam and fentanyl in patients undergoing awake fiberoptic intubation. Indian $\mathrm{J}$ Clin Anaesth 2019;6(2):235-41. 